\title{
The Production of Brailled Instructional Materials in Texas Public Schools
}

\section{Tina S. Herzberg and Laura M. Stough}

Abstract: This study investigated the background of personnel who are responsible for transcribing braille in Texas. Most respondents were not certified by the Library of Congress and believed that they had begun their careers less than adequately prepared, yet they rated the quality of the materials that they produced as either excellent or good.

Braille transcribers translate information from a print source into a braille version for persons who are blind or have low vision. Until the mid-1990s, the training of braille transcribers and the materials that they produced received little attention in the research literature. However, the National Agenda for the Education of Children and Youths with Visual Impairments, Including Those with Multiple Disabilities (Corn, Hatlen, Huebner, Ryan, \& Siller, 1995) and the formation of the American Foundation for the Blind (AFB) Textbooks and Instructional Materials Solutions Forum (American Foundation for the Blind, 1998) emphasized the importance of gaining access to braille materials. These entities sought to increase the number of qualified braille transcribers, to examine the issues of insufficient instructional materials in braille, and to address the shortage of braille transcribers in the United States.
Consequently, the forum commissioned a national survey, and AFB funded two landmark studies on braille transcription.

One of these studies, by Corn and Wall (2002), explored the training and employment of braille transcribers throughout the United States. Surveys were sent to all 50 states, and specialists in the area of visual impairments from 40 (80\%) states responded. The results supported anecdotal reports of a shortage of braille transcribers and projected a continued shortage of transcribers in the United States. In that study, $76 \%$ of the directors of instructional materials centers, state vision consultants, and superintendents of special schools in 40 states thought that their states did not have a sufficient number of transcribers to meet their needs (Corn \& Wall, 2002). Furthermore, the respondents reported that approximately 350 additional transcribers were needed nationally to 
meet needs for braille of students, particularly those who are competent in both the Nemeth code and tactile diagrams. The study also estimated a continued and perhaps even more critical shortage of braille transcribers within the next 5 to 10 years.

Despite evidence of a nationwide shortage, access to transcribers in the classroom appears to vary from state to state. In a study of 233 teachers of students with visual impairments in Florida, only 37\% of the respondents reported that transcribers were available to assist them in preparing materials (Allman \& Lewis, 1996). In contrast, in a study of 51 teachers of students with visual impairments in Minnesota (or slightly more than $50 \%$ of all teachers of students with visual impairments in that state), all 51 teachers reported that they had access to a braille transcriber (Knowlton \& Berger, 1999). A pilot study of 10 highly academic braille-reading high school students found that their teachers used braille transcribers extensively to produce materials for 8 of the students (Leigh \& Barclay, 2000). In contrast, a study of 107 teachers of students with visual impairments in 41 states found that only $35 \%$ of the teachers had a transcriber available to assist them in preparing materials (Rosenblum \& Amato, 2004).

Since the majority of states do not have a sufficient number of certified transcribers, they typically employ a wide variety of alternatively trained personnel. Certified transcribers, noncertified transcribers, volunteers, paraprofessionals, and teachers of students with visual impair- ments are regularly used to transcribe materials into braille (Allman \& Lewis, 1996; Corn \& Wall, 2002; Texas Education Agency, 2000; Wall \& Corn, 2002). In addition, a variety of options are available across the states for training teachers and other personnel in braille (Corn \& Wall, 2002), including a correspondence course from the National Library Service for the Blind and Physically Handicapped (NLS), locally developed courses, on-thejob training provided by individual employers, college courses, and the independent study of textbooks (Corn \& Wall, 2002). Corn and Wall (2002) found that $41 \%$ of the specialists rated their current training methods as effective, $36 \%$ rated their efforts as ineffective, and $18 \%$ stated that their training efforts were neither effective nor ineffective. In a comprehensive study of transcribing in Texas, the most used training options, in order of frequency, were the NLS correspondence course, on-the-job training by teachers of students with visual impairments, braille courses sponsored by Education Service Centers, and college courses (Texas Education Agency, 2000).

When aides and paraprofessionals are initially assigned to transcribe materials, teachers of students with visual impairments (who may or may not be certified by NLS) are often assigned the task of training these paraprofessionals (Allman \& Lewis, 1996; Curry \& Hatlen, 1989). In Texas, this option is the most commonly used method for training novice braille transcribers (Texas Education Agency, 2000). Although this method has not been evaluated in the literature, the 
effectiveness of this approach obviously varies greatly and is highly dependent on the teacher-trainer's skills in braille transcribing.

Although most teachers of students with visual impairments value braille as an important instructional medium, their transcribing skills may fluctuate across the length of their careers. For example, if teachers do not use braille for an extended period, their braille skills may deteriorate. The results of Amato's (2002) survey of teacher-trainers in the United States and Canada lend credence to this conjecture: More than $70 \%$ of the 45 respondents thought that a teacher's competence is a function of continuing braille practice. Forty-two of these 45 respondents also believed that refresher braille courses should be required at regular intervals or when a teacher thinks it is necessary to refresh his or her skills. However, this practice is not required in any state. Because of the low incidence of students who read braille in public schools, teachers of students with visual impairments may not teach a student who is a braille reader for several years. For example, Allman and Lewis (1996) found that 51\% of the teachers of students with visual impairments in their study were not currently using braille with students. Similarly, DeMario and Lian (2000) reported that $22 \%$ of the 205 teachers of students with visual impairments in Illinois and Massachusetts in their study had no students who read braille. The braille skills of teachers who have not had recent braille practice cannot be expected to be as fluent as those of teachers who use braille daily.

A teacher's proficiency as a transcriber is important, even if most transcribing for a student may be done by a transcriber. For example, in a pilot study of teachers who served students who read braille, all five teachers reported that they regularly transcribed some materials themselves. These teachers estimated that they spent .5 to 15 hours per week transcribing, with an average of 2 hours per week, even though four of the five teachers had access to a braille transcriber (Leigh \& Barclay, 2000). Similarly, 23 teachers of students with visual impairments in Colorado reported that they spent an average of almost $10 \%$ of their time adapting and brailling materials (Correa-Torres \& Howell, 2004).

States use a variety of methods to determine proficiency in transcribing braille, which makes it difficult to compare the skills of transcribers. Corn and Wall (2002) reported that, in the United States, braille proficiency is usually assessed by certification by NLS, a review of the transcriber's work, feedback from consumers, and state examinations. Texas determines proficiency by NLS certification, a review of the transcriber's work, and an examination (Texas Education Agency, 2000). Unlike other states, employers in Texas may also use a grade on a braille course to determine proficiency (Texas Education Agency, 2000). Although many employers use measures to determine initial proficiency, they do not assess the quality of braille on an ongoing basis, so there is no assessment of a transcriber's level of 
proficiency over time. Similarly, NLS certification, university examinations, and grades in braille courses do not require the reexamination of skills beyond the initial demonstrated level of proficiency.

Little is known about the production of braille instructional materials in Texas public schools, specifically, what instructional materials are transcribed into braille or who is responsible for transcribing these materials. The quality of these braille instructional materials has become particularly critical, since approximately $70 \%$ of the students with visual impairments in the United States are served in general education classrooms (U.S. Department of Education, 2002). General education classrooms typically use a variety of instructional materials, such as teacher-made tests, worksheets, ancillary workbooks, and novels, in addition to textbooks. Although textbooks are usually transcribed at the state level, local personnel usually transcribe other instructional materials into braille. Since most public schools do not review the quality or readability of these materials, little is known about the quality of the transcribed materials that are produced by the school districts. Materials that have not been transcribed appropriately may affect the literacy of students who read braille. It has been anecdotally hypothesized that students who read braille receive materials that are not equal in quality to those received by sighted students. (This theory is supported by Corn and Wall [2002].) The purpose of the project reported here was to discover who is responsible for transcribing instructional materials in Texas public schools, how these personnel were trained, and the process by which they transcribe these instructional materials into braille.

\section{Method}

This project was part of a larger study that examined the backgrounds of school district personnel who are responsible for transcribing braille in Texas and the actual quality of the materials that they produce. Initially, it used an electronic survey to collect information about the demographic characteristics and training of the personnel and to determine how print materials are transcribed into braille. In this project, the following research questions were investigated:

1. Who transcribes instructional materials into braille in Texas public schools?

2. What is the training and certification level of persons who transcribe instructional materials into braille in Texas public schools?

3. How are print materials transcribed into braille in Texas public schools?

4. How do those who transcribe materials rate their own accuracy?

Afterward, approximately half the respondents of the initial survey submitted a braille transcription of two print worksheets. To investigate the quality of materials that they actually produced, the second part of the study involved an in-depth 
error analysis of the transcriptions. A focus group then reviewed the transcriptions and assessed the legibility and readability of these transcribed materials.

\section{RESPONDENTS}

The respondents in the larger project were approximately 140 school personnel who were responsible for transcribing literary materials into braille in Texas public schools. They included teachers of students with visual impairments, transcribers, aides, and paraprofessionals. Only those personnel who were employed to transcribe print into braille during the 2005-2006 academic year by an independent school district, a regional service center, or the Texas School for the Blind and Visually Impaired were included.

At the beginning of this investigation, the authors estimated that 130 to 150 braille transcribers were employed in Texas. According to the most recent report by the Texas Education Agency (2000), school districts, Education Service Centers, and nonprofit businesses employed 24 certified transcribers and 105 noncertified transcribers during 1999-2000. All active braille transcribers for Texas schools were sent an anonymous survey via e-mail.

\section{INSTRUMENT}

The survey began with a brief description of the purpose of the study and contained 24 items that were divided into five sections. The opening section contained demographic items that asked the respondents to identify their sex, job title, level of education, certification status, and braille reading proficiency. The next section asked them about their training. The third section requested information about the types of materials that they were currently transcribing. Some of the questions in the second and third sections were modeled after surveys designed by the AFB Textbook and Instructional Materials Solutions Forum (AFB, 1998) and the Texas Education Agency (2000). In the fourth section, the respondents were asked about the process by which they transcribed materials. The last section asked them to rate their perceptions of the quality of the materials that they transcribe at their schools. The survey was designed to be completed in less than 10 minutes.

A draft of the instrument was initially e-mailed for review to three NLScertified transcribers, a regional consultant for people who are visually impaired, and the vision consultant of the state of Texas. Suggestions for modification included clarification of wording, additional resources that are commonly used by transcribers, and one typographical error. The revised instrument was then reviewed by four university faculty members, which resulted in additional clarification of the items.

\section{Procedures}

The first author began recruitment for the study by sending an e-mail message to the consultants at each of the 20 Education Service Centers in Texas. The e-mail message explained the purpose of the project, included the electronic link for the survey, and asked the Education Service 
Center consultants to report the number of braille transcribers who worked in public schools in their region. It also requested that the consultants forward the e-mail message and link to all braille transcribers and other personnel who routinely transcribed braille in their region. Once the Education Service Center consultants forwarded the materials, they were asked to send an e-mail message to the researcher confirming that they had forwarded the information. Since the state school also served several braille readers, an e-mail message explaining the purpose of the project was sent to the principal of the school. It included the electronic link to the survey, and the principal forwarded the e-mail message to school personnel who transcribed instructional materials for individual students.

Two weeks later, a follow-up e-mail message with the same information was sent to the Education Service Center consultants who had not yet confirmed that they had sent out the survey. When confirmation was not received within one month for 2 of the 20 educational regions, the researcher directly contacted these consultants at a statewide Education Service Center meeting. As a result, 14 additional survey responses were received.

\section{Results}

The first research question focused on understanding who transcribes instructional materials into braille in public schools. Potential respondents were given the option of completing the survey elec- tronically or in hard copy. Of the estimated 120 e-mail-distributed surveys that were sent, 98 were returned electronically. Of the 98 respondents, only 4 (4.1\%) reported that they spent no time each week transcribing instructional materials into braille, and these 4 responses were not included in the final database. Therefore, 94 surveys were used in the analysis of the data. The characteristics of the 94 respondents are presented in Table 1.

The survey also collected data about the professional background, including training and certification level, of persons who transcribe instructional materials into braille. The respondents who reported that they were certified were asked what types of certifications they held. Of the 92 who responded to the question, $10.9 \%(n=10)$ were certified as braille transcribers, and $89.1 \%(n=82)$ were not. All 10 certified respondents reported that they were certified by the Library of Congress as literary braille transcribers. Two of the 10 certified transcribers noted that they were also certified in the Nemeth code by the Library of Congress. No respondent reported being certified in the areas of braille music or proofreading.

The respondents were asked, given a 40-hour workweek, how much time they spent transcribing print materials into braille each week. Table 2 details the data on the percentage of time the respondents spent transcribing each week. Ten respondents provided a range of time rather than an estimate. These responses were averaged using the low and high number of 
Table 1

Characteristics of the respondents $(n=94)$.

\begin{tabular}{lcc}
\hline Variable & $\begin{array}{c}\text { Response } \\
\text { Number }\end{array}$ & Percentage \\
\hline Job title & & 43.6 \\
Teacher of visually impaired students & 41 & 23.4 \\
Braillist & 22 & 13.9 \\
Paraprofessional or aide & 13 & 10.6 \\
Transcriber & 10 & 4.3 \\
Dually certified teacher and orientation & & 2.1 \\
and mobility specialist & 4 & 2.1 \\
Orientation and mobility specialist & 2 & 5.3 \\
Other & 2 & 29.8 \\
Level of education & 5 & 4.3 \\
High school diploma or GED & 28 & 30.9 \\
Some college & 4 & 29.8 \\
Associate's degree & 29 & 13.8 \\
Bachelor's degree & 28 & 25.5 \\
Master's degree & & 35.1 \\
Years of experience & 13 & 9.6 \\
0-1 & 24 & 5.3 \\
2-5 & 33 & 9.6 \\
6-10 & 9 & 1.1 \\
$11-15$ & 5 & \\
$16-19$ & 9 & \\
$20+$ & 1 & \\
No response & & \\
\hline
\end{tabular}

hours that they listed. Of the 91 respondents who answered this question, the time spent transcribing braille each week ranged from 1 hour to 45 hours, with a mean of 8.67 hours and a median of 10 hours. In general, the teachers of students with visual impairments reported spend- ing less time each week transcribing than did the transcribers or braillists.

Data were also collected on the types of training received by the 93 respondents who answered the question (see Table 3). The respondents were directed to choose more than one response if they had

Table 2

Time spent by the respondents transcribing print materials into braille each week (percentage).

\begin{tabular}{|c|c|c|c|c|}
\hline $\begin{array}{l}\text { Time } \\
\text { (in hours) }\end{array}$ & $\begin{array}{c}\text { Teachers of } \\
\text { students with } \\
\text { visual impairments } \\
(n=41)\end{array}$ & $\begin{array}{c}\text { Transcribers } \\
\quad(n=10)\end{array}$ & $\begin{array}{l}\text { Braillists } \\
(n=22)\end{array}$ & $\begin{array}{l}\text { All other } \\
\text { respondents } \\
(n=21)\end{array}$ \\
\hline $1-10$ & 80.49 & 20.0 & 9.0 & 52.3 \\
\hline $11-20$ & 14.63 & 0.0 & 13.6 & 33.3 \\
\hline $21-30$ & 0.00 & 10.0 & 4.5 & 9.6 \\
\hline $31-40+$ & 2.44 & 60.0 & 68.4 & 4.8 \\
\hline No response & 2.44 & 10.0 & 4.5 & 0.0 \\
\hline
\end{tabular}


Table 3

Types of training completed by the respondents $(n=93)$.

\begin{tabular}{lcc}
\hline Training options & Number & Percentage \\
\hline University or college training & & \\
$\quad$ One braille course designed for teachers & 37 & 39.8 \\
Two or more braille courses designed for teachers & 19 & 20.4 \\
$\quad$ One or more braille courses designed for & 6 & 6.5 \\
$\quad$ transcribers & & 52.7 \\
Nonuniversity training & 49 & 48.4 \\
$\quad$ Workshops focusing on braille transcribing & 45 & 34.4 \\
On-the-job training sessions & 32 & 10.8 \\
Conference sessions on braille transcribing & 10 & 18.3 \\
Correspondence course & 17 & \\
Other & & \\
\hline
\end{tabular}

completed more than one type of training. The most commonly reported types of training were workshops that had focused on braille transcribing $(n=49)$ or on-thejob training $(n=45)$. The vast majority $(n=85)$ of respondents had received training in the literary braille code, and slightly more than $75 \%(n=69)$ had received training in the Nemeth code. Fewer respondents reported that they had received training in formatting $(n=49)$, proofreading $(n=32)$, computer braille $(n=27)$, and music braille $(n=8)$.

Another question asked the respondents to evaluate how well their training had prepared them to transcribe braille. Of the 91 who responded, $28.6 \%(n=26)$ thought that they had learned most of what they needed to know on the job, $22 \%(n=20)$ reported that there were many gaps in their training that they had to fill once they began their jobs, $27.5 \%$ $(n=25)$ believed that there were some gaps in their training that they had to fill in once they began their jobs, and $20.9 \%$ ( $n=19)$ said that their training had provided them with all the information they needed to do their jobs. Only 1 participant reported that she had not received any training before she began her job.

Almost $80 \%$ of the respondents stated that they had begun their transcribing careers less than adequately prepared. Additional comments at the end of the survey partially explain these results. One respondent wrote, "I was extremely unprepared with one course in my certification classes. I am still brailling with minimal formatting. Graphics are [my] biggest concern." Several other respondents noted the difficulty of obtaining training in the advanced aspects of braille transcribing. One commented, "I have found that it is easier to get training on the beginning levels of braille transcription, but high[er]-level trainings are few and far between." The lack of training in the Nemeth code for math and science material was specifically mentioned. Another respondent added, "I have complained for years that there needs to be somewhere to get Nemeth instruction. The Library of Congress does not allow you to go through the Nemeth [course] without getting the literary certification." 
Table 4

Types of materials transcribed by respondents.

\begin{tabular}{lccc}
\hline Type of materials & Often & Sometimes & Never \\
\hline Teacher-produced worksheets and & 70 & 24 & 6 \\
$\quad$ handouts $(n=90)$ & 68 & 21 & 11 \\
Classroom tests $(n=90)$ & 29 & 17 & 54 \\
State-adopted ancillaries $(n=78)$ & 26 & 39 & 35 \\
Novels assigned by general education & & & \\
$\quad$ teachers $(n=84)$ & 22 & 33 & 44 \\
Nonstate-adopted textbooks $(n=81)$ & 19 & 32 & 49 \\
Nonstate-adopted ancillaries $(n=78)$ & 18 & 30 & 52 \\
Standardized tests $(n=79)$ & 13 & 48 & 39 \\
Library books $(n=82)$ & 9 & 31 & 60 \\
State-adopted textbooks $(n=80)$ & & & \\
\hline
\end{tabular}

The most frequent types of materials prepared by these school district personnel were classroom tests, teacherproduced worksheets, and handouts (see Table 4). State-adopted textbooks, standardized tests, and state-adopted ancillaries were rarely or never prepared by the majority of the respondents. Materials for language arts were transcribed into braille more frequently than were materials in other subject areas.

The third question focused on how the participants prepared print materials into braille. The respondents were asked what resources and specialized technology, such as the Perkins braillewriter, or computer programs they used when they transcribed the materials into braille. More than $90 \%(n=91)$ reported that they often or sometimes used the Perkins braillewriter to transcribe materials. In addition, almost $80 \%(n=65)$ reported that they often or sometimes used Duxbury Braille Translation software. MegaDots software $(n=44)$, direct-entry computer programs $(n=12)$, and Braille 2000 software $(n=$ $5)$ were less commonly used tools.
The next question asked the respondents which support materials they used when preparing materials in braille. Of the 86 respondents, $54.7 \%(n=47)$ used the Braille Enthusiast's Dictionary (Koenig \& Holbrook, 1995), 39.5\% $(n=34)$ used such publications as the NBA [National Braille Association] Braille Formats Course (National Braille Association, 2002), and $38.4 \%(n=33)$ used the NLS correspondence course, Instruction Manual for Braille Transcribing (Risjord, Wilkinson, \& Stark, 2000). Almost 33\% $(n=28)$ consulted the New Programmed Instruction in Braille (Ashcroft, Henderson, Sanford, \& Koenig, 1994; Ashcroft, Sanford, \& Koenig, 2001), and an identical number reported that they use Braille Formats: Principals of Print to Braille Transcription (Braille Authority of North America, 1997b). Almost 13\% $(n=11)$ reported that they use Braille Codes and Calculations (Pesavento, 1993). The least commonly used resources $(n=3$ and $n=$ 2, respectively) were Hadley School for the Blind's professional development courses and The Computerized Nemeth 
Code Tutor (Kapperman, Henry, Cortesi, Heinze, \& Sticken, 1997).

Of the 86 respondents who answered the question, 31 indicated "other," a category that included a variety of formal resources that were not included in the list. The most common resource $(n=11)$ mentioned in the "other" category was The Nemeth Braille Code for Mathematics and Science Notation (American Printing House for the Blind, 1972). Eight respondents also listed other publications from the American Printing House for the Blind, such as the Nemeth code reference sheet (undated) and Guidelines for Tactile Graphics (Otto, 1997). Three others indicated that they used the Braille Code for Chemical Notation (Braille Authority of North America, 1997a).

Several informal resources were also included in the "other" category. Three respondents indicated that they used unattributed handouts and braille "cheat sheets," and two respondents reported that they used self-created cheat sheets. Three respondents reported that they contacted another transcriber whenever they had questions. One respondent said that she used the Internet as a resource. With regard to how frequently they consulted resources while preparing materials, the 91 respondents answered as follows: almost always (5.5\%), often (39.6\%), sometimes $(39.6 \%)$, rarely $(13.2 \%)$, and never $(2.2 \%)$.

Two questions focused on how the respondents proofread the materials they prepared for their students. The majority of respondents stated that they regularly proofread their transcriptions. In a follow-up question, slightly less than $20 \%$ $(n=17)$ reported that they had someone else proofread their materials on a regular basis.

The last research question focused on the perceived accuracy of print transcribed into braille. The survey included an item that was designed to elicit the respondents' perceptions of the quality of the braille instructional materials that they produced. Of the 89 respondents who answered the question, $91 \%(n=81)$ rated the quality of the braille materials that they produced as being either excellent or good, $9 \%(n=8)$ rated their materials as fair, and none rated their materials as poor.

\section{Discussion}

A significant body of research has indicated that a wide variety of school personnel, including teachers of students with visual impairments, paraprofessionals, aides, and dually certified teachers of students with visual impairments and orientation and mobility specialists, are responsible for transcribing instructional materials into braille (Allman \& Lewis, 1996; Corn \& Wall, 2002; Leigh \& Barclay, 2000; Rosenblum \& Amato, 2004; Texas Education Agency, 2000; Wall \& Corn, 2002). The results of this study similarly found a wide variety of personnel with one noteworthy addition: $25 \%$ of the respondents reported that they were braillists. Like transcribers, braillists transcribe information from a print source into a braille version. The job title of braillist may be unique to Texas; in other 
states, terms such as transcriber, paraprofessional, or teaching assistant may be used to describe personnel in comparable positions.

More than $40 \%$ of the respondents were teachers of students with visual impairments. As was found in studies from other states (Correa-Torres \& Howell, 2004; Leigh \& Barclay, 2000), this finding illustrates that teachers of students with visual impairments often transcribe instructional materials that their students need. When these teachers have this responsibility, their preservice training needs to be comprehensive, and they must ensure that their transcribing skills remain proficient throughout their teaching careers.

As was the case in Corn and Wall's (2002) study, the training experiences of the respondents in this study varied greatly, and few respondents were certified by the Library of Congress. A significant finding was that almost $80 \%$ of the respondents stated that they had begun their transcribing careers less than adequately prepared. Despite this bleak beginning, it appeared that most of the respondents had participated in a variety of continuing education opportunities. Eighty-one of the 93 respondents reported that they had attended workshops or conference sessions on braille transcribing. The most commonly reported types of training were workshops focusing on braille transcribing, on-the-job training, and a single braille course that was designed for teachers during the teachertraining segment of their education. It is perhaps because of these continuing educational experiences that $91 \%$ of the re- spondents self-rated the quality of their braille as good or excellent at the time of this study. Further studies should investigate the extent to which self-ratings accurately reflect the quality of the braille that is actually produced.

Similar to the responses reported by Rosenblum and Amato (2004), several respondents noted the difficulty of obtaining training in the more advanced aspects of braille transcribing, especially the Nemeth code for math and science materials. As one experienced respondent commented, "I feel I produce excellent braille most of the time. However, I do get concerned when transcribing chemistry since no actual training is available in this area." Some preservice training programs combine both the literary braille and the Nemeth codes into a single university course (Amato, 2002; Rosenblum \& Amato, 2004), which may not allow adequate time to teach formatting or the Nemeth code. Some of the respondents' comments suggest there is a need to provide ongoing opportunities for training in the Nemeth code. Further research should also directly examine the quality of Nemeth code materials produced by public schools.

It appears that personnel in Texas continue to transcribe a wide variety of materials, ranging from teacher-produced worksheets, classroom tests, stateadopted ancillaries, and nonstate-adopted textbooks to novels that are assigned by general education teachers. It is not surprising that the transcription of classroom tests and teacher-produced handouts were the two most frequently named materials 
in this study, as was the case in the 2000 report of the Texas Education Agency. The majority of the respondents reported that they use computers and brailletranslation software programs at least part of the time when transcribing materials. An even larger number of respondents reported that they still use the Perkins braillewriter when preparing at least some materials.

\section{LiMitations}

Since there is no database of braille transcribers who worked for Texas public schools, the first author relied on intermediaries to obtain the sample. Each of the 20 Education Service Centers in Texas had a designated consultant who worked with teachers of students with visual impairments and braille transcribers. These consultants were usually in close contact with teachers and paraprofessionals who served students with visual impairments. However, if they did not have a complete, updated listing of e-mail addresses for braille transcribers in their region, the survey may not have reached all the transcribers and teachers of students with visual impairments at different school districts throughout Texas.

The second limitation is that the survey focused on braille production in a single state. Given the variance in certification practices and educational terminology from state to state, the results from just one state were collected. However, given the size of the state and the historical access to a number of good-quality braille-preparation programs in the state, we believed that the findings would par- allel those from other states with similar braille-certification standards.

\section{Recommendations}

According to the data provided by the respondents, there seems to be no universal standard or consistent format that is used in training school personnel to transcribe instructional materials into braille in Texas. This finding may be especially problematic, since almost $80 \%$ of the respondents also stated that they had begun their transcribing careers less than adequately prepared. For personnel to be equipped to provide students with accurate and properly formatted braille materials, minimal standards for personnel should be created, competence in braille transcribing should be formally defined, and training should be standardized.

None of the respondents indicated that he or she had participated in online, university, or locally developed refresher braille courses; this may be an additional option for districts to explore. As was the case with teachers who participated in braille transcription training by the Florida Department of Education (Allman \& Holbrook, 1999), refresher braille courses could be another practical option when teachers and transcribers need to update, reinforce, or expand their skills. Given that some teachers may have several years when they are not using their braille skills, these courses may help ensure that their skills remain current.

Finally, a direct examination of instructional materials in braille should be conducted to determine if the self-ratings 
of the quality of braille provided by the school personnel that were surveyed reflect the actual quality of braille materials used in the classroom. A direct examination of braille materials, including math, science, and music, may provide valuable direction to training programs on how to teach personnel to prepare high-quality brailled materials. Information about patterns of errors may be used to evaluate and perhaps improve both preservice and in-service training programs for teachers of students with visual impairments and braille transcribers. Future research should also investigate the quality of materials that are prepared with direct-entry methods versus brailletranslation software to determine if brailletranslation software and other technological solutions should be emphasized during training.

\section{References}

Allman, C. B., \& Holbrook, M. C. (1999). Providing a braille refresher course for teachers of students with visual impairments. Journal of Visual Impairment \& Blindness, 93, 770-777.

Allman, C. B., \& Lewis, S. (1996). Content validity of the National Literary Braille Competency Test. RE:view, 28, 103-112.

Amato, S. (2002). Standards for competence in braille literacy skills in teacher preparation programs. Journal of $\mathrm{Vi}$ sual Impairment \& Blindness, 96, 143152.

American Printing House for the Blind. (1972). The Nemeth braille code for mathematics and science notation. Louisville, KY: Author.

American Foundation for the Blind. (1998). AFB Textbook and Instructional Materials Solutions Forum. Retrieved on April 25, 2007, from http://www.afb.org/ Section.asp?SectionID $=44 \&$ TopicID $=16$. Ashcroft, S. C., Henderson, F., Sanford, L., \& Koenig, A. (1994). New programmed instruction in braille (2nd ed.). Germantown, TN: Scalars.

Ashcroft, S. C., Sanford, L., \& Koenig, A. (2001). New programmed instruction in braille (3rd ed.). Germantown, TN: Scalars.

Braille Authority of North America. (1997a). Braille code for chemical notation. Louisville, KY: American Printing House for the Blind.

Braille Authority of North America. (1997b). Braille formats: Principals of print to braille transcription. Louisville, KY: American Printing House for the Blind.

Corn, A. L., Hatlen, P., Huebner, K. M., Ryan, F., \& Siller, M. A. (1995). The national agenda for the education of children and youths with visual impairments, including those with multiple disabilities. New York: AFB Press.

Corn, A. L., \& Wall, R. S. (2002). Training and availability of braille transcribers in the United States. Journal of Visual Impairment \& Blindness, 96, 223-232.

Correa-Torres, S. M., \& Howell, J. J. (2004). Facing the challenges of itinerant teaching: Perspectives and suggestions from the field. Journal of Visual Impairment \& Blindness, 98, 420-433. 
Curry, S. A., \& Hatlen, P. H. (1989). Low incidence disability programs quality study: Visually impaired version. Sacramento: Special Education Division, California Department of Education.

DeMario, N. C., \& Lian, M. J. (2000). Teachers' perceptions of the need for and competency in transcribing braille materials in the Nemeth code. Journal of Visual Impairment \& Blindness, 94, 7-14.

Kapperman, G., Henry, G., Cortesi, M., Heinze, A., \& Sticken, J. (1997). The computerized Nemeth code tutor [software tutorial]. Sycamore, IL: Research and Development Institute.

Knowlton, M., \& Berger, K. (1999). Competencies required of braille teachers. RE:view, 30, 151-159.

Koenig, A. J., \& Holbrook, M. C. (1995). The braille enthusiast's dictionary. Germantown, TN: Scalars.

Leigh, S. A., \& Barclay, L. A. (2000). High school braille readers: Achieving academic success. RE:view, 32, 123131.

National Braille Association. (2002). Braille formats course. Rochester, NY: National Braille Association.

Otto, F. (1997). Guidelines for design of tactile graphics. Louisville, KY: American Printing House for the Blind.

Pesavento, M. E. (1993). Braille codes and calculations: A self-study workbook for teachers, parents, and paraprofessionals who wish to learn the literary and mathematical braille codes. Oakland, CA: Pesavento Press.
Risjord, C., Wilkinson, J., \& Stark, M. L. (2000). Instruction manual for braille transcribing (4th ed.). Washington, DC: Library of Congress.

Rosenblum, L. P., \& Amato, S. (2004). Preparation in and use of the Nemeth braille code for mathematics by teachers of students with visual impairment. Journal of Visual Impairment \& Blindness, 98, 484-495.

Texas Education Agency. (2000). Training and availability of braille transcribers. Unpublished raw data.

U.S. Department of Education. (2002). Twenty-third annual report to Congress on the implementation of the Individuals with Disabilities Education Act. Washington, DC: Author.

Wall, R. S., \& Corn, A. L. (2002). Production of textbooks and instructional materials in the United States. Journal of Visual Impairment \& Blindness, 96, 212-222.

Tina S. Herzberg, Ph.D., assistant professor and director, Visual Impairment Program, School of Education, University of South Carolina Upstate, 800 University Way, Spartanburg, SC 29303; e-mail: $<$ therzberg@uscupstate.edu>. Laura M. Stough, Ph.D., associate professor, Department of Educational Psychology, Texas A\&M University, 704 Harrington Tower, Mail Stop 4225, College Station, TX 77843-4225; e-mail: <lstough@ taтu.edu>. 